\section{International Journal of

DOI: 10.31695/IJASRE.2019.33449

\title{
Benchmarking Energy consumption in Nigeria Universities
}

\author{
Utazi, Divine. $N^{1}$, Unachukwu, Godwin. $O^{2}$. and Ani, Hillary. $0^{3}$. \\ ${ }^{1}$ Department of Mechanical Engineering, Madonna University Nigeria \\ ${ }^{2}$ Department of Mechanical Engineering, University of Nigeria \\ ${ }^{3}$ Department of Mechanical Engineering, Caritas University Amorji-Nike Enugu, Nigeria
}

\begin{abstract}
That energy is an important development factor is now common knowledge. Without energy, services and societal activities will virtually grind to a halt. In Nigeria, there are several federal and state universities that receive their funding from the government. Because of their peculiar nature as knowledge-transfer-based institutions, the energy source predominantly in use in the universities is electricity. Therefore, the issues of electric energy availability, consumption and costs in universities with resident students and staff quarters can present a formidable challenge to any responsible administration. Due to the inadequate and epileptic supply of electricity in our universities, this paper establishes the need for baseline energy consumption profile in the Universities as a framework for future energy savings scheme and policy formation. This will help to identify where energy is being wasted, together with appropriate energy efficiency measures that can be considered in order to reduce energy consumption, costs and mitigate associated environmental externalities.
\end{abstract}

Keywords: University, Benchmarking, Energy efficiency, Policy and Nigeria.

\section{INTRODUCTION}

Electricity is fundamental and inevitable to our daily living as it lightens our environment, powers our homes, schools, hospitals, offices, businesses, and promotes industrialization. Stable energy supply is of vital importance for the wealth of a country. [1]

Universities in Nigeria are designed like a small-scale town where staff and students largely reside within the learning environment. In this regard, housing infrastructure and other facilities necessary for teaching and research are developed and provided for within the envelope. To drive the entire system for effective knowledge transfer, provision of energy (especially electricity) and water become a necessity. Although grid electricity supply to the Universities is inadequate and epileptic, the grey issue of great concern appears to be the level of inefficiency in its consumption by the University community. In addition to the situation is the ever-rising unit cost of energy and increases in students' enrolment over the years. Attention has yet to be paid as to what could be done and how to reduce energy wastes and ameliorate the burden of energy bill increases on the University administration.

Furthermore, the need to reduce the carbon footprint of the Universities in the new paradigm of climatic change has become imperative.

The system set up shows that Universities purchases bulk electricity from the national grid and distributes same to staff housing units, students' hostels, academic and non-academic buildings, business entities located within the environment and other energy users in the system. It is instructive to note that most buildings within these Universities are not metered. This makes it impossible to quantify the level of energy consumption and user behaviour in those outfits. The need for responsible energy consumption in the Universities has become more compelling viewed against the backdrop of inadequate funding support and increasing infrastructural development.

Gladly enough, advances in renewable energy technology (particularly solar energy) have opened a broader window of opportunities to address some of the energy issues in some critical service areas in the Universities. But this can be adequately addressed only if the levels of energy use in such cost centres are methodologically assessed, thus the need for energy benchmarking in order to provide a framework for possible energy policy in the Universities in Nigeria. 


\section{UNIVERSITY ENERGY NEEDS AND THEIR ROLE IN SUSTAINABLE DEVELOPMENT}

\subsection{University Energy Needs}

Large institutions, such as universities, consume large amounts of energy on a daily basis. Improving the energy practices at postsecondary institutions can not only directly decrease their environmental impact but also act as an example for change across the country. Because of their peculiar nature as knowledge transfer-based institutions, the energy source predominantly in use in the universities and other tertiary institutions for educational aids is electricity [2]. Therefore, the issues of electric energy availability, consumption and costs in universities with resident students and staff quarters can present a formidable challenge to any responsible administration. This is because its availability or otherwise can have profound effects not only on academic activities but also on the social and economic activities in the system [3].

In Universities, there is a considerable amount of population, including students, academic and non-academic staff, researchers, and others who work or study in universities. Thus, energy is needed for teaching and research, provision of support services, hostel areas, senior staff housing units of various grades (flats, bungalows, and duplexes) and junior staff housing units. The University community is indeed a mini-township.

The University campuses, being a miniature city consumes so much energy for lighting, water supply, air-conditioning, ventilation, electrical heating equipment, and water heaters, amongst others. Conserving this energy will lead to a reduction in energy consumption, operating costs, lesser lighting fixture replacements and reduction in accumulated heat generated by them, thereby leading to parts of the drive towards mitigating climate change and making buildings more environmentally sustainable [4].

Most Universities receives funding from the Federal and State Government through the National Universities Commission. However, due to continuing adjustments in government's economic policies, coupled with high students' enrolment, growing infrastructural development, and demand for better conditions of service etc, financial releases from the government are no longer sufficient to meet the growing needs of energy in the universities. The situation, therefore, calls for every laudable measure that will reduce spending. One of such identified measures certainly is improving end-use energy consumption in the system [2].

\subsection{Role of Universities in Sustainable Development}

A university is an institution with a global outreach that brings into cohesion the best brains for the good of the society. In general terms, the University is a citadel of learning and has remained the major player in the development of human capital and infrastructure of nations. Research, on the other hand, is an introspective and retrospective activity to furnish a solution to a problem or improving the existing method of achieving a goal. It is driving the spirit of enquiry, exploration, invention, discovery or development. Although, these attributes are express in many activities at a different rate. In the modern era, scientific research appears to be one area that has affected humanity substantially, that is why the Universities everywhere in the world are the home of diverse research activities. The Universities in Nigeria has performed marvelously well since inception, from the colonial era till now. The Nations University had been bringing out research findings, from the laboratories, workshops, studio and other experimental facilities which are vital for the development of the country.

As institutions for research, teaching and policy development, with their influence and resources, universities play an important role in promoting sustainable development. In a time faced with increasing environmental challenges, the tertiary sector is being recognized as well suited to take on the leadership for environmental protection [5]. By greening their own campuses, higher institutions can teach and demonstrate the principles of awareness and stewardship of the natural world, as well as increase the chances of clean and pleasant local and global environments for the future [6].

However, 'greening of Universities' is a complex and relatively new field of research, further studies are needed to investigate and analyze energy use on University campuses, and thereby help the institutions realize that 'going green' has numerous advantages. A green university can furthermore become a green model for the external community by gathering and sharing effective ideas on environmental issues and practices.

\section{CONCEPT OF ENERGY EFFICIENCY}

Energy efficiency is a concept expressed by a set of measures or the effects of these measures whose objective is a reduction of energy consumption such that consumer satisfaction is maintained. Energy efficiency is not simply confined to the management of demand, but can also be applied to production, transportation and distribution of energy [7]. A common indicator of energy efficiency is the index of energy intensity which measures the quality of energy required to generate one dollar unit of aggregate output [8]. The lower the value of energy intensity, the more efficient and economy. However, energy efficiency also means an improvement in practice and products that reduce the energy necessary to provide services like lighting, cooling, heating, manufacturing, cooking, transport, entertainment, etc. Energy efficiency products essentially help to do more work with less energy [9]. Energy efficiency is also defined as essentially using less energy to provide the same service [10]. In this sense, energy efficiency can also be thought of as a supply resource - often considered an important, cost-effective near to midterm supply 
option. Investment in energy efficiency can provide additional economic value by preserving the resource base (especially combined with pollution prevention technologies) mitigating environmental problems [11].

Energy efficiency improvements may provide an opportunity to reduce energy consumption and consequent greenhouse gas emissions to bridge the gap between current emissions and the reductions necessary to prevent serious effects of climate change as predicted by the

Intergovernmental Panel on Climate Change (IPCC) [12]. Energy efficiency improvements exist that are readily available, can have negative costs, and can immediately reduce energy consumption and consequent greenhouse gas emissions as has been demonstrated by Enkvist (in what has now become known as the "McKinsey Curve") as well as by Rubin and others [13],[14],[15],[16]. Unfortunately, without a better understanding of energy consumption, these improvements may not be full.

Studies like [17], [18], [19], [20] and [11] have x-rayed the importance of an efficient energy sector to a developing economy like Nigeria, and how to improve this efficiency by adopting different methodologies to conserve and curb vampire losses.

In a related development, [21] in his paper on energy efficiency programmes recommended an enabling environment around capacity building, energy audit /assessment, energy codes and standards-energy labeling, research development and demonstration, energy pricing/efficiency policy etc.

\section{CONCEPT OF ENERGY BENCHMARKING}

\subsection{Energy Benchmarking}

Benchmarking informs organizations about how they use energy, where they use it, and what drives their energy use. It is a key step in identifying opportunities to increase profitability by lowering energy and operating costs. Benchmarking is necessary for effective energy management. Through benchmarking, the key metrics for assessing performance are identified, baselines are established, and goals are set. This process helps to identify the key drivers of energy use and provides an important diagnostic tool for improving performance.

By evaluating trends and variability in energy use, benchmarking can improve management decisions on investments in energyrelated projects. Developing a historical perspective on current and past energy use provides a context for those decisions. Benchmarking against the industry provides key insights into the competitive use of energy. Benchmarking demonstrates the value of an energy program and prospects for additional savings. It enables an organization to understand the opportunities lost by the remaining average in energy performance and the benefits of progressing beyond the average [22].

\subsection{Benchmarking Methods Overview}

Energy benchmarking methods can be either top-down or bottom-up [23]. The bottom-up methods evaluate energy consumption on the disaggregated level while top-down methods on aggregated level [24]. Depending on the methods, the input data require information such as the physical characteristics of the dwellings, occupants and their appliances, historical energy consumption, climatic conditions, and macroeconomic indicators [25].

The bottom-up methods look at various related components to estimate their individual impact on energy usage. Bottom-up methods provide information on how energy is used in the building for different purposes. The breakdown information on end-use is valuable when targeting energy-saving goals.

According to [24], bottom-up methods can be based on statistical data or building physics. Both require a comprehensive database of empirical data for each disaggregated component.

The bottom-up statistical methods usually rely on monthly billing data and information on all energy end-uses. The end-use by different components can be achieved using survey and/or sub-metering [26]. One of the beneficial results associated with installing sub-meters is that giving occupants' feedback on energy consumption can alter their habits and reduce energy end-use.

The top-down methods looking at buildings as a whole; thus, require little detail of the actual consumption processes [25]. Input data are relatively simple compared with bottom-up methods. Many top-down benchmarking methods can be based on total utility bills and single or multiple measures. The historical bills can reflect the factor of random occupant behaviour. The outdoor drybulb temperature is widely used as a single measure. The multiple measures can be temperature parameters and/or building characteristics. For example, the study by [27] used multiple measured including outdoor dry-bulb temperature, humidity and horizontal solar radiation to model building energy use.

The downside of using historical consumption information is that it does not necessarily predict future trends, especially under recent noticeable changing climate and technology updates. Moreover, general information used for top-down analysis is not sufficient to provide possible retrofit strategies [28]. 


\section{CONCLUSION}

In Nigeria, there is a lack of sufficient organized research materials and data that will guide the development of policy and legislation that will strengthen the efficient use of energy. Also, there is a lack of sufficient material to conduct training on energy efficiency. All these points to the poor development of the concept in Nigeria. The absence of coordinated and organized research materials and data to feed into the Bill and other legal instruments to enable it to meet the needs and objectives of energy efficiency programs has inhibited the development of energy efficiency.

Better data about energy consumption can empower consumers and policymakers to more efficiently facilitate reductions in energy consumption. Without first understanding how energy is currently being used it is unlikely that consumers and policymakers can maximize energy consumption reductions. It is also important to have access to baseline data in order to properly gauge the effectiveness of energy efficiency programs.

\section{REFERENCES}

[1]. Obuka, Nnaemeka S.P., Utazi, Divine N., Onyechi, Pius C., Agbo, Cornelius O. (2014). Electric-Power Energy Situation and the Need for Implementing Energy Efficiency Measures in Nigeria: A Review. International Journal of Emerging Trends in Engineering and Development Issue 4, Vol.1, Pp 407-413

[2]. Godwin Ogechi Unachukwu (2010). Energy Savings Opportunities at the University of Nigeria, Nsukka. Journal of Energy in Southern Africa Volume 21 Number 1

[3]. Tang, F.E (2012), 'An Energy Consumption Study for a Malaysian University', World Academy of Science, Engineering and Technology International Journal of Environmental, Ecological, Geological and Mining Engineering Vol.6 No: 8, 99 - 105

[4]. Manjunatha, P.M, Balachandra, T.C, Dsouza, O, Naik, B (2013), 'Energy Audit, Conservation and Power Factor Improvement for BMSIT Campus', International Journal of Research in Engineering and Technology, Vol.2 (11), Pp 354-359

[5]. Leal Filho, W., F. MacDermott, and J. Padgham, (1996), Implementing Sustainable Development at University Level: A Manual of Good Practice. Association of European Universities- Copernicus.

[6]. Creighton, S.H. (1998), Greening the Ivory Tower: Improving the Environmental Track Record of Universities, Colleges and Other Institutions. MIT Press.

[7]. Adenikinju, A. (2010). The efficiency of the Energy Sector and its Impact on the Competitiveness of the Nigeria Economy. International Association for Energy Economics, Pp 27-31.

[8]. Eberhard, A., Foster, V., Briceno-Garmendia, C., Ouedraogo, F., Camos, D., and Scharatan, M. (2008). Underpower: The State of the Power ElSector in Sub-Saharan Africa, Annex 2: Country Tables. Report Produced as Part of the African Infrastructure Diagnostic Study.

[9]. Schutze, E., and Worthington, R. (2002). Getting to Grips with Sustainable Energy. Publication of the Sustainable Energy and Climate Partnership.

[10]. Rosen, M.A. (2008). Towards Energy Sustainability: A Quest of Global Proportion. Forum of Public Policy Online. A Journal of the Oxford Round Table.

[11]. Obuka, Nnaemeka S.P., Utazi, Divine N., Onyechi, Pius C., and Agbo, Cornelius O. (2014). Electric-Power Energy Situation and the need for Implementing Energy Efficiency Measures in Nigeria: A Review. International Journal of Emerging Trends in Engineering and Development Issue 4, Vol.1

[12]. Dillahunt, Tawanna, Jennifer Mankoff, Eric Paulos, and Susan Fussell. (2009). "It's not all about green: Energy use in lowincome communities." In Proceedings of the 11th international conference on Ubiquitous Computing, pp. 255-264. ACM.

[13]. Kollmuss, Anja, and Julian Agyeman. (2002) "Mind the gap: why do people act environmentally and what are the barriers to pro-environmental behaviour?." Environmental education research 8, no. 3: 239-260.

[14]. Gardner, Gerald T., and Paul C. Stern. (2008). "The shortlist: The most effective actions US households can take to curb climate change." Environment: Science and Policy for Sustainable Development 50, no. 5: 12-25. 
[15]. Riche, Yann, Jonathan Dodge, and Ronald A. Metoyer. (2010). "Studying always-on electricity feedback in the home." In Proceedings of the SIGCHI Conference on Human Factors in Computing Systems, pp. 1995- 1998. ACM.

[16]. Attari, Shahzeen Z., Michael L. DeKay, Cliff I. Davidson, and Wändi Bruine de Bruin. (2010). "Public perceptions of energy consumption and savings." Proceedings of the National Academy of Sciences 107, no. 37: 16054-16059

[17]. Ayodele, A.S. (1998), Energy Crisis in Nigeria: The case of Electric Energy Market. Bullion Publication of CBN, 22(4), 1923.

[18]. MEFL (2011); Victorian Energy Efficiency Target(VEET). Retrieved from:www.mefl.com.au

[19]. Croucher, M. (2010a), Are Energy Efficiency standards within the Electricity Sector a form of Regulatory Capture? Seidman Research Institute W.P. Carey School of Business Arizona State University.

[20]. Chevron (2011), Energy Efficiency and conservation; Chevron Energy Solutions (CES), 2010-2011Chevron Corporation.

[21]. Sambo, A.S. (2007), Creating an Enabling Environment for Energy Efficiency Programmes in Nigeria; World Energy Council- Africa Forum on Energy Efficiency 8th -9th January Abuja Nigeria.

[22]. Benchmarking to save energy. https://www.energystar.gov/ia/business/healthcare/Benchmarking to_Save Energy.pdf. (Retrieved 20th December 2015).

[23]. Bohringer, C., Rutherford, T. F. (2008). Combining bottom-up and top-down. Energy Economics, 30(2), 574-596.

[24]. Kavgic, M., Mavrogiani, A., Mumovic, D., Summerfield, A. J., Stevanovic, Z., \& Djurovic-Petrovic, M. (2010). A review of bottom-up building stock models for energy consumption in the residential sector. Building and Environment, 45, 1683-1697.

[25]. Swan, L. G., \& Ugursal, V. I. (2009). Modelling of end-use consumption in the residential sector: a review of modelling techniques. Renewable and Sustainable Energy Reviews, 13, 1819-1835.

[26]. Wilson, D., \& Swisher, J. (1993). Exploring the gas: top-down versus bottom-up analyses of the cost of mitigating global warming. Energy Policy, 249, 64.

[27]. Reddy, T. A., \& Claridge, D. E. (1994). Using synthetic data to evaluate multiple regression and principal component analyses for statistical modelling of daily building energy consumption. Energy \& Buildings, 21(1), 35-44.

[28]. Perez-Lombard, L., Ortiz, J., Gonzalez, R., \& Maestre, I. R. (2009). A review of benchmarking, rating and labelling concepts within the framework of building energy certification schemes. Energy and Buildings, 41(3), 272-278. 